and non-academic personnel-areas in which industry appears to have a comparative advantage.

These observations lead to certain conclusions. First, neither the industrial research centres, the quasi-Government laboratory, nor the university is the ideal organization for basic research; all are undergoing rapid expansion, and all can be improved. All need to examine both their objectives and their operation critically and should make basic studies about 'organizational design' as well as scientific research. For example, the industrial research centre may need to take on some additional activities in fundamental science, or to co-operate more closely with universities in basic research. In return, the universities might consider turning over to industry some of the activities which contribute only marginally to basic research. The quasi-Government organizations need to find a more secure role for themselves and their people. All these organizations draw on the same pool of human capital, and Prof. Harbison emphasizes that it is in the American interest that there be rational thinking about how best to use this precious form of capital.

Secondly, the selection and development of managers in all three types of organization needs more careful attention. Management, in itself, is a kind of profession, in that a successful administrator to-day needs some basic knowledge of principles of organization, human behaviour, motivation and techniques of personnel administration. $\mathrm{He}_{\theta}$ cannot acquire these on the job by experience alone. He must study these systematically, although the concepts of management which are used in administration of corporations are not always appropriate for the administration of laboratories.

The third and final conclusion stems from the other two. The effective selection and development of managerial personnel is dependent on a basic understanding of the nature of research organization, the expectations of different kinds of scientists, and the improvements in design which are necessary for building an effective organization. Only when this is done is there any reliable basis for selection of managers and for the kind of training required to improve their effectiveness.

Systematic analysis of organizational design and managerial development, therefore, is fundamental for effecting better utilization of scientific manpower. To enable this to be done, Prof. Harbison recommends that every sizeable laboratory, whether industrial, Government or university, should have at least one highly competent person devoting his major energies to analysis of organizational and manpower development problems. This man should not be involved in the routine operations of personnel administration. He should report directly to the chief executive officer of the laboratory as a top policy adviser. If possible, he should have had some experience with managerial problems. More important, he should know the laboratory, enjoy the unqualified respect of its scientific personnel, and possess the capacity and interest to analyse human relation. ships systematically with both insight and imagination.

\title{
UNIVERSITY OF OXFORD SOUTH CASPIAN EXPEDITION
}

$\mathrm{A}$ PARTY from the University of Oxford, with the support of the University of Tehran, made a biological survey of the eastern Caspian coast of northern Iran and the neighbouring Elburz Mountains (long. $52^{\circ}-54^{\circ}$ E., lat. $35^{\circ} 40^{\prime}-37^{\circ}$ N.) during AugustSeptember 1961. The primary objective was to discover the extent and pattern of bird and insect migration through the region.

Detailed observations of bird movements and fluctuations in numbers were made on the Mian Kaleh peninsula, on the Firuz Kuh and Imamzadeh cols, and in the intervening mountain passes and coastal plain by R. W. Arnold, R. S. Bailey, P. P. Feeny and R. J. Olliver of the University of Oxford, and Dr. E. Etemad of the University of Tehran. Altogether, 200 species of birds were recorded from the region during the period of fieldwork. Southerly day-migration through the mountain cols involved a variety of species, but generally small numbers. On the coast, by contrast, both variety and numbers wore far greater, and extensive movements of duck, waders, terns and hirundines were regularly noted. Largest concentrations of passerine night-migrants were found in the hedgerows and woodland of the coastal plain, and included both south-westerly migrants, exemplified by Sylvia borin and $S$. communis, and south-easterly migrants such as Muscicapa parva, Phylloscopus nitidus and Emberiza aureola. This last species has probably not been previously recorded from northern Persia. The significance of the observations is at present being examined, with particular reference to weather, topography and the distribution of the various species.
A small and selective collection of bird skins was made, chiefly comprising wheatears, Oenanthe spp., and yellow wagtails, Motacilla flava, of which at least three races are represented (almost certainly $M . f$. lutea, $M . f$. thunbergi and $M . f$. melanogrisea). In addition, 226 birds of 38 species were trapped with mist-nets and marked with British Museum rings, in the hope of obtaining further information about the directions of migration.

Daily observations of insect migration were carried out by S. L. Sutton, who also took nightly samples with the aid of mercury vapour traps, powered by a portable generator. Many of the Lepidoptera species were definitely migratory, while others were probable migrants. In particular, the butterfly Danais chrysippus chrysippus, previously thought to have a much more southerly distribution, was found in numbers, with some movement to the south. It was seen to come in from the sea, and was also noted moving through the Elburz Mountains at 7,000 ft. The moth Utetheisa pulchella appeared in large numbers on the Caspian coast at the end of August and was afterwards found inland. Many of the other species recorded are well-known migrants of cosmopolitan distribution. A collection of more than 500 specimens of Lepidoptora and other insocts is at present being examinod at the British Museum. The collection includes several little-known species from $9,000 \mathrm{ft}$. in the Elburz Mountains, where mercury vapour trapping was highly successful.

Although botanical collecting was not one of the main objects of the expedition, it was decided to collect a limited number of plants from the region for 
the Royal Botanic Garden at Edinburgh, in connexion with work being carried out there on the flora of Middle-eastern countries. The area has been little visited by botanists, particularly during the late sunimer. C. J. C. Rees collected 200 species from a wide variety of habitats. A predominance of composites and caryophyllaceous plants was noticeable at high altitudes, and many plants at 8,000-9,000 ft. showed xerophytic adaptations. Below the mainly deciduous rain forest zone, no particular family preponderance could be seen, though the variety of species was here much greater. The collection is largely composed of Compositae, Papilionaceae, Scrophulariaceae, Labiatae, Gramineae and Caryophyllaceae, though about 27 other families are repre- sented. The opportunity was also taken, at the request of the Royal Horticultural Society, to collect about 100 bulbs. These, mainly Liliaceae, were found by C. J. C. Rees at 7,000 ft. near Firuz Kuh.

More than $5,000 \mathrm{ft}$. of colour $16-\mathrm{mm}$. ciné film was exposed in the region. In addition to the fieldwork of the expedition, the film shows many of the birds and insects, as well as some of the activities of the local population, including sturgeon-fishing, cottonpicking and rice-harvesting. The work of the expedition has been further documented with a large collection of colour transparencies and black-and-white photographs.

P. P. FeEny

S. L. SuTtoN

C. J. C. ReEs

\section{SWISS SOCIETY FOR NATURAL SCIENCES}

$\mathrm{T}$ HE one hundred and forty-first annual session of the Swiss Society for Natural Sciences was held at Bienne (Biel) during September 22-24, 1961. While the majority of members approached the town by river steamer up the great Rhine tributary Aar, a small group, already in Bienne, were privileged to see over one of the famous watch factories of the district, Omega, which leads the world in the degree of automation already introduced. As is now traditional, a nearby beauty spot had been chosen for the first general assembly: Douanne (Twann), reached by lake paddle-steamer, passing the beautiful Isle SaintPierre, part wildly wooded, part vine-clad, Switzerland's largest island, made famous by J.-J. Rousseau since his stay during September 12-October 25, 1765, and a place of pilgrimage from that time forth for admirers of his passionate philosophy of Nature.

At the opening administrative session, the central president, Prof. Gian Töndury (Zollikon), reported, inter alia, his attendance as delegate at the Royal Society's Tercentenary Celebrations, but regretted the lack of contact there with Royal Society members, a disappointment afterwards offset by a return delegation from the Royal Society to Switzerland. Prof. Töndury dropped into his native Romansch to announce the invitation from Schuls (Engadine) for the annual session 1962, under the direction of Dr. Th. Zingg (Davos).

The general proceedings opened with the address of the annual president, Dr. H. Schilt (Bienne), on the central theme of the session, "Symétrie et Forme". Illustrating the æsthetic aspect for both artist and intellectual, he stressed the simplification due to symmetry in mathematical problems and the characteristic dissymmetries contrary to expectation, such as between electric and magnetic fields. His concluding remarks on music and on the discovery by Walther Frey, the psychologist, of hidden symmetries in Bach's works ushered in a most apposite and fascinating performance of the "Art of the Fugue" by a local amateur quartet.

The invited speeches (which will appear in full in the Actes) were "Symmetrie in den Naturgesetzen", by Prof. J. M. Jauch (Geneva); "Symmetrie und Unordung in der Kristallwelt", by Prof. F. Laves (Swiss Federal Institute of Technology, Zurich); "Symmetrie und Form der Tiere", by Prof. F. E. Lehmann (Berne); "Sur la génése des formes symétriques et asymétriques chez les végétaux supérieurs", by Prof. L. Plantefol (Paris), together with a striking film on the disposition of leaves presented by Prof. $O$. Schluepp (Reinach), epitomizing his now well-known life-work. All these speakers leaned on the ancient idea of symmetry as law in general, an invariance in time, rather than a geometrical mirror principle in particular, and they underlined the approximateness and elusiveness of its embodiment in Nature, by contrast with the abstract structures of man's mind. Even in these structures, as Prof. Jauch pointed out, ancient preconceptions on the inner harmony of Nature had to go before progress became possible and a more subtle symmetry was revealed. It is important, too, to realize that although natural laws may show symmetry, initial boundary conditions do not; moreover, noticeably in newest nuclear physics, the symmetry of the existing laws is never fully exploited.

On the concrete side, Prof. Laves showed with the aid of slides how in erystal growth distortion and geometrical symmetry are allied, preserving 'rationality rules'. By entertaining juxtapositions, he exhibited the resemblance between spontaneous crystal formations and specimens of modern art. The æsthetic appeal of a deliberate combination of order with disorder was even more strikingly demonstrated in the old masters, notably Dürer. Prof. Lehmann stressed the analogy between faunal evolution and crystal formation, with the two added characteristics of adaptation and a huge time-factor, involving an enormous number of purely repetitive generations. For the examination of the 892,000 species in the major divisions of the animal kingdom, elassical morphology, though now out of date, must of course not be discarded out of hand; but shape must be related to environmental features. A totalization process must displace the meticulous attention to detail in observation; in the laboratory, reconstructed forms of life, developed from plankton, have already demonstrated the feasibility and fruitfulness of experiment where observable specimens are lacking in the evolutionary scale. The same point of view for the realm of plants was taken by Prof. Plantefol as had been stressed by Prof. Lehmann for the animal reign, namely, the basic status of each individual kind as a systematic carrier of life. His exposition, with slides, gave a vivid account, closely reasoned, of his historic discovery (now known to every botanist) that growth is not from one vegetative point at the plant apex, but from a ring around it. Both symmetries and dissymmetries were explained 